Círculo de Lingüística Aplicada a la Comunicación

ISSN: $1576-4737$

http://dx.doi.org/10.5209/CLAC.56328

\title{
Taipei 2017: International Conference on English for Specific Purposes
}

http://english.scu.edu.tw/esp2017

Cómo citar: Taipei 2017: International Conference on English for Specific Purposes. Círculo de Lingüistica Aplicada a la Comunicación 70, 271. http://www.ucm.es/info/circulo/no70/taipei.pdf. http:// dx.doi.org/10.5209/CLAC.56328

Waishuangxi Campus, Soochow University, Taipei, Taiwan, November 3-4, 2017 Due date for abstract submission: July 17, 2017

Notification of abstract acceptance: August 14, 2017

We welcome papers on (new) trends in researching and teaching of English for Specific Purposes (ESP). The domain of ESP has had a strong research tradition since its inception in the 1960s. With the increasing demand for big data analyses, application of multi-media and information technology, and ESP translation and interpreting, we will use this international conference as a platform to discuss emerging (new) trends and needs for researching and teaching. We solicit works on conventional themes: the socio-discourse, the socio-culture and the socio-politics, highlighting genre-informed pedagogy, situated learning as well as critical pedagogy respectively. In addition, we also need (new) teaching and research directions for all three social turns of ESP in Asian and other contexts. 